\title{
¿QUÉ NECESITAN LOS PACIENTES?
}

Francisca J. Hernández Martín

M uchas preguntas y no tantas respuestas para reflexionar acerca del fenómeno humano que llamamos RELACIÓN. Comunicación, diálogo, empatía, cercanía, acogida, respeto, tiempo..., interés. ¿Qué postula la relación humana y qué hacer para establecerla?

Son preguntas que nunca encuentran una respuesta perfecta, la relación humana es personal entre al menos dos seres humanos, pero ¿es esto suficiente? ¿Qué hacer para establecerla y qué hacer cuando existe problema en la relación? El tópico de que los seres humanos somos muy complejos, no es suficiente para justificar una mala relación o una dificultad en la relación. Un profesional de la Enfermería para cuidar ha de conocer qué le pasa a los pacientes y para ello es imprescindible cuidar la relación.

En la vida cotidiana surgen problemas, y también problemas de relación, que al profesional no le es fácil establecerla. Todos tenemos experiencia de la facilidad y dificultad, como también de la perplejidad, que provocan ciertas reacciones, palabras o hechos de los pacientes y del no saber qué hacer o cómo encontrar respuesta, si la tiene, y ¿qué hacer con aquello que no tiene respuesta?

Los tratados sobre la relación humana, fundamentados en la filosofía, psicología, antropología, psicoanálisis..., y los estudios llevados a cabo sobre ciertas experiencias en el tema nos dan una idea teórica y razonada del fenómeno y, aunque esto es esencial, por sí solo no garantiza que tengamos lo suficiente para dar respuesta a estos interrogantes. Los problemas que nos plantean en la práctica no tienen una respuesta fácil y general, dado que la relación es siempre personal y original.

Aceptado que la relación es un fenómeno complejo, nos viene inmediatamente una primera pregunta, ¿qué es lo esencial en la relación?

Es posible comentar muchas anécdotas y experiencias. Lo presentado a continuación nos dejó desbordados y con muchas preguntas a quienes fuimos testigos de excepción. Nunca olvidaré lo presenciado en la habitación de un hospital.
Junto a mi hermano, ingresado la noche anterior con un ACVA (un trombo en una arteria cerebral) del que g. a D. se recuperó sin dejarle secuela alguna, había dos ancianos, Roberto en la cama de la derecha y Domingo en la cama de la izquierda.

Roberto, además de diagnosticado de una hernia de hiato, padecía demencia senil y quien tenía a su lado, pendiente del movimiento de sus labios a su esposa, una mujer de una gran sensibilidad, una paz y serenidad inalterables, que dejó ver en algunos momentos sus puntos de vulnerabilidad. Día y noche estuvo aguantando las duras palabras de su esposo, que en medio de la demencia no dejaba de llamarle p... y derivados en todos sus grados. La mujer, sorda, captaba mejor que nadie cuanto le decía. Y permanecía con humor dando respuesta a las necesidades de su esposo.

El segundo, Domingo, solo, sin compañía ni visita de su familia (al menos en el tiempo que permaneció en dicha habitación) que, ingresado por otro problema digestivo y también con una demencia acentuada, permanecía agitado pero en silencio. Estaba conectado a una bomba de perfusión, sonda nasogástrica, y vesical y no hacía sino tirar e intentar, en la medida de su fuerza, quitársela. Toda la noche permaneció en un sillón, arrastrándolo hasta la puerta de la habitación y por supuesto tirando de las sondas. No hubo forma de acostarle en la cama, incluso cuando al final se consiguió, se bajó él sólo de la cama al sillón.

Los profesionales, entraron cuantas veces fue necesaria su intervención sin escatimar trabajo ni esfuerzo alguno para tranquilizar a estos dos ancianos y atenderles. Profesionales competentes, humanos y con una paciencia admirable.

Yo permanecí al lado de mi hermano desde su ingreso, que necesitaba tranquilidad para recuperarse de cuanto le había ocurrido la noche anterior. Por tanto, pude ser testigo de todo el proceso. La descripción hecha de la situación nos da idea de cómo estábamos a las $9 \mathrm{~h}$. de la mañana los ocupantes de dicha habitación cuando llegó el desayuno. 
Bajo estos efectos, a las $10 \mathrm{~h}$. entró la señora de la limpieza. Abre la puerta, para realizar su trabajo y saluda con unos "buenos días" y rostro risueño. Conforme se adentra se encuentra con la negativa del primero a tomar alimento y aproximándose, a los pies de la cama, le dice: A TI, ¿QUÉ TE PASA? ¿QUÉ TE HAN HECHO?

No recuerdo si hubo respuesta por parte del paciente, pero su cara se iluminó. Sus ojos quedaron pendientes del rostro de la señora y se quedó tranquilo. Parecía otro, como si todo hubiese pasado y ahora alguien diese luz y sentido a su vida. Cualquiera que hubiese presenciado los minutos anteriores como síntesis de toda la noche, no hubiese dado crédito a lo que allí viese u oyese. La señora con una mirada sonriente, viva, expresiva, como quien sabe de estas cosas, realizó su trabajo y antes de ir a la otra parte de la habitación apostilló, "mañana vendré a verte". Roberto pasó al menos la mañana como si fuese otro, la mirada viva como si hubiese sido iluminada por alguien en quien confiase. ¿Qué pasó en aquel anciano? ¿Qué le dio demás esta señora que su esposa, quien pasó días y noches a su lado? No lo sabemos, pero lo cierto es que por un tiempo ese hombre se tranquilizó y pudo ser lo que era antes. Un hombre cargado de años, y enfermo.

Si fue sorpresivo y elocuente lo ocurrido a la derecha no lo fue menos cuanto ocurrió a la izquierda. La señora, fregona en mano, se dirigió a este hombre y le dijo: $\measuredangle Y$ A TI DOMINGO, QUÉ TE PASA? ¿POR QUÉ ESTÁS ASÍ? Si el rostro del primero se iluminó, el del segundo se transformó, se confió plenamente a la señora quien sin dejar de limpiar el polvo de la cama y el suelo, finalizada su tarea le miró para asegurarle lo mismo que al anterior: "mañana, Domingo, vengo a verte". Con estas palabras salió de la habitación como quien ha cumplido con su obligación, pero no sé si tan consciente de que había dejado a dos ancianos sosegados, confiados a su palabra-promesa, que no se cumplió, pero que estos dos ancianos eran otros.

Acerca de Roberto, ¿qué le faltó tanto por parte de su esposa como del personal? ¿Qué pudo darle la señora que fue a cumplir su misión, la limpieza de la habitación? ¿El interés que mostró por él?, ¿llevaba algo más su mirada y su sonrisa? ¿Captó y comprendió su situación? Pero, ¿no había interés y comprensión e incluso buen humor en su esposa que permaneció no sólo atenta, sino con un tono poco frecuente, dado el tiempo que llevaba sin salir del Hospital y sin mostrar un gesto de cansancio? Aún no salgo de mi asombro sobre qué pudo provocar en el anciano el "¿a ti, que te pasa?, ¿qué te han hecho?"

A los dos días llegó su hija, una mujer joven, madura, educada, sensible, paciente que mantuvo en todo momento la actitud y gesto de cercanía y cariño hacia su padre. El anciano, mantuvo la misma actitud que con su esposa y la trató de la misma forma. Sin embargo, el gesto de la hija no cambió a pesar de ello y de que venía desde muy lejos a sustituir a su madre para que ésta pudiese descansar. De Roberto supe, posteriormente, que su hija tenía una Residencia de ancianos y él no quería ir allí. En su demencia, ¿pudo sospechar que el Hospital fuera la residencia? ¿Pudo deberse a esto la actitud agresiva hacia su hija?, y ¿hacia su esposa? ¿La miraba como cómplice? ¿Pudo pesar esto, además de su demencia, en su actitud?

Pero, ¿y Domingo? ¿Qué pasaba con Domingo? Nadie de su familia lo visitó en esos tres días ¿Podría haber algo similar? No lo sé, pero este hecho me ha llevado a reflexionar acerca del tema, sobre todo ¿qué aporta la sonrisa, el interés y la comprensión?, pues pueda que sean algunas de las claves, pero ¿qué necesitaban estos pacientes que ni la familia ni el personal se lo dio y que alguien, pudiéramos decir más de paso, acertó?

Podemos poner en pie muchas hipótesis y muchas respuestas. Pero lo que para mi sigue latente es la pregunta inicial, ¿Qué postula la relación humana y qué hacer para establecerla? y otra no menos esencial queda pendiente: ¿Qué necesitan los pacientes? 